\title{
Conjunciones y disyunciones en Octavio Paz y José Revueltas
}

\author{
Evodio Escalante \\ Universidad Autónoma Metropolitana \\ evos46@hotmail.com
}

\begin{abstract}
RESUMEN: Este artículo explora algunas de las iniciales coincidencias tanto en la poesía y en la biografía, como en la formación política y cultural de los escritores Octavio Paz y José Revueltas, detectables sobre todo en sus años de juventud. Señala que un texto poco conocido de Marx, los Manuscritos económico-filosóficos de 1844, que se traducen en México por primera vez en 1939, tiene un fuerte impacto que llega a reflejarse en lo que ambos escritores publican. Su evolución filosófica empieza a divergir de modo claro a partir de los ańos cincuenta, con la adscripción surrealista de Paz y sus lecturas heideggerianas de esa época, mientras que Revueltas permanecerá fiel a un marxismo de fuertes tendencias hegelianas.
\end{abstract}

Palabras Clave: Octavio Paz; José Revueltas; Romanticismo; Marxismo; Surrealismo; Hegel; Heidegger.

ABSTRACT: This paper explores some of the initial coincidences in the poetry and the biography and also in the political and cultural breeding of the writers Octavio Paz and José Revueltas that one could find in their youth years. It points out to a scarcely known book by Marx, the Economic and Philosophic Manuscripts of 1844, which was translated in México for the first time in 1939, and that impacts strongly in the texts that both writers do publish. Later, their philosophical evolution shows signs of divergence when in the fifties Paz joins in one part the surrealistic movement and in the other begins to read Heidegger's work, whilst Revueltas stands faithful to his strongly hegelian lecture of Marx.

KeYwords: Octavio Paz; José Revueltas; Romanticism; Marxism; Surrealism; Hegel; Heidegger.

FeCha de ReCerción: 4 de febrero de 2016.

FeCHA DE ACEPTACión: 20 de mayo de 2016.

unque personalidades en gran medida antitéticas en las que relum-
enra un genio específico, sorprenden las coincidencias y afinidades
entre Octavio Paz y José Revueltas. No sólo nacen los dos en el año de 
la "Toma de Zacatecas" por el ejército campesino que dirigía Francisco Villa y en que tuvo lugar la Convención de Aguascalientes, acontecimientos que señalan el punto más alto de la participación de las clases desposeídas en el proceso de la Revolución mexicana, sino que son hijos ambos de familias radicalizadas de una clase media venida a menos a consecuencia de los reacomodos políticos y de los cambios que experimenta el país. Si en el primero resulta más que decisiva la influencia de su padre, el abogado zapatista Octavio Paz Solórzano, fundador al lado de Antonio Díaz Soto y Gama del Partido Nacional Agrarista, en Revueltas el papel adoctrinador correrá a cargo de su hermano el pintor y muralista Fermín Revueltas, fundador del Grupo ;30-30! y de la revista comunista El Machete (1924). Ambos estudian en colegios privados. Revueltas cursa los primeros cuatro años de la primaria en el Colegio Alemán, y luego se pasa a la educación pública al fallecimiento del padre; Paz estudia en una escuela de lasallistas y continúa en el Colegio Williams, que administran unos hermanos de procedencia inglesa. Ambos desertan de los estudios cuando falta la autoridad paterna. Revueltas deja la escuela muy pronto, en 1925, en que decide estudiar por su cuenta en la Biblioteca Nacional y pasar algunas de sus tardes libres en las oficinas de El Machete leyendo revistas y libros de la ideología comunista; Paz abandona la carrera de Leyes que estaba a punto de terminar en 1937, dos años después del trágico fallecimiento de su padre en las inmediaciones de Santa Marta Acatitla. Ambos viajan muy jóvenes al extranjero. Revueltas a Moscú en 1935, en que participa como delegado en el VI Congreso de la Internacional Juvenil Comunista; Paz a Valencia en 1937 como invitado al Congreso de Escritores Antifascistas en apoyo de la causa de los republicanos españoles. También muy jóvenes, ambos realizan "trabajo de campo" en el estado de Yucatán, uno de los epicentros de la Reforma Agraria promovida por el presidente Lázaro Cárdenas (1934-1940). Al abandonar la carrera de Derecho, Paz se enrola como profesor en una escuela para obreros y campesinos en la ciudad de Mérida; Revueltas hará algo semejante apenas un año después. Inspirados por esta experiencia que los remite a la pobreza de los campesinos henequeneros, los dos escriben poemas que expresan una profunda inquietud revolucionaria no ajena a "arranques" de carácter nihilista: anhelan la destrucción del viejo orden para que nazca uno nuevo. Ahí en Mérida, Paz escribe los borradores iniciales de un poema social que bien podría ser su primera pieza realmente maestra, Entre la 
piedra y la flor (1941). Este poema, que contiene una notable imprecación contra el capitalismo y el imperio del dinero, y que inaugura entre nosotros una peculiar edad del poema lírico que se muestra capaz de convivir con un impulso de temple manifestario sin perder por ello su naturaleza poemática, inicia su último canto con esta exhortación destructiva: "Dame, llama invisible, espada fría, / tu persistente cólera, / para acabar con todo, / oh mundo seco, / oh mundo desangrado, / para acabar con todo" (Paz 2014a: 101-108). ${ }^{1}$

El poema de Revueltas, que data de esos mismos años, y que fue escrito - hay que señalarlo- con absoluta independencia del de Paz que no será publicado sino cuatro ańos más tarde, reproduce una muy semejante ansia de destrucción que deja entrever análoga afinidad transformadora, como si a través de la exhortación lírica fuese posible acabar con una realidad que se experimenta como agobiante e injusta: "Es preciso, es preciso, es preciso que se caigan los muros, / que cesen los venablos de angustia que nos han atravesado, / que quede nada más un grito clamando, herido eternamente, / y una sobrehumana colérica voluntad como ramas de un árbol furioso / para golpear hasta el polvo y el aniquilamiento" (Revueltas 2001: 25-28). ${ }^{2}$ El poema del joven Paz quiere acabar con todo; el de José Revueltas golpear hasta el polvo y el aniquilamiento. Están de acuerdo sin haberse puesto de acuerdo.

Si bien el sexenio de Cárdenas con su fraseología y su acción reformadora e incluso socializante es básico en su conjunta formación, tanto Paz como Revueltas dan señas de una notable precocidad que ya los encuentra "politizados" desde finales de la década de los veinte, o sea, desde la época del llamado "Maximato". La radicalidad de Paz tiene que ver con una suerte de "comunismo agrarista", que hereda de su progenitor, a quien había acompañado siendo muy niño en su destierro voluntario en los Estados Unidos; la de Revueltas, con el comunismo proletario que lo lleva a ingresar en las juventudes del Partido Comunista. En su libro Poeta con paisaje, Guillermo Sheridan sostiene de modo tajante que Octavio Paz "habría participado, como buena parte de la juventud educada de la clase media capitalina, en la campaña de Vasconcelos para la presidencia en 1929". Aunque es cierto que Sheridan se corrige él mismo de inmediato al aclarar: "No mucho, la verdad, pues era muy

\footnotetext{
${ }^{1}$ Al calce del texto, Paz anota: "Yucatán, 1937 / México, 1940".

2 El poema data al final: "Octubre de 1937".
} 
joven y su participación fue acaso en calidad de muchedumbre que gritaba ‘Viva Vasconcelos!' por las calles” (92); me temo que su dicho responde más a la fantasía de un ensayista que intenta hacer biografía que a una realidad comprobable. Si Paz hubiera simpatizado con la campańa de Vasconcelos, no hubiera tenido impedimento para reconocerlo él mismo en su libro autobiográfico Itinerario. Ahí, al referirse al año crucial de 1929, omite de modo significativo toda mención a este movimiento. Afirma, en cambio: "Yo tenía quince años, terminaba mis estudios de iniciación universitaria y había participado en una huelga de estudiantes que paralizó la universidad y conmovió al país" (Paz 1993: 46-47). Es todo, y se explica. Ni Revueltas ni Paz tendrían por qué sentirse invitados a participar en una campaña "reformista" como la de Vasconcelos, que había sido — no se olvide- alto funcionario del régimen del que ahora tomaba distancia, cuando ellos tenían puestas sus simpatías en causas más radicales como sin duda lo eran las de Emiliano Zapata y Carlos Marx.

En efecto: otro aspecto que los hermana es su fervorosa y temprana lectura de Marx. El fallecido colega Jorge Fuentes Morúa demostró de manera fehaciente que a Revueltas lo deslumbró a finales de los años treinta la lectura de los Manuscritos económico-filosóficos de 1844, traducidos por primera vez al español por Alicia Gerstel Rühle y José Harari, un escritor argentino y una exiliada centroeuropea que habría llegado a México acompañada de su esposo Otto Rühle para escapar de la persecución nazi en Alemania. ${ }^{3}$ La predilección de Revueltas por el concepto de enajenación así como su casi obsesivo vínculo con la dialéctica de Hegel, provienen sin duda de esta lectura que lo habrá de acompañar toda su vida y que se refleja en algunas de sus novelas como Los días terrenales (1949) y Los errores (1964), se explicita en su famoso Ensayo sobre un proletariado sin cabeza (1962) y culmina en plena madurez del autor con la Dialéctica de la conciencia (1982), cuya publicación es póstuma.

${ }^{3}$ Ella se suicidaría en México horas después de la muerte de su marido en 1943. El título exacto de la publicación es Carlos Marx, Economía politica y filosofía. Relaciones de la economía politica con el estado, el derecho, la moral y la vida burguesa. México: Editorial América, s/d. Por información obtenida revisando la revista Futuro, que publicaba Vicente Lombardo Toledano, puede colegirse que el libro empezó a circular durante los primeros meses de 1939 . 
De hecho, el primer texto teórico-doctrinario que Revueltas da a las prensas es ya una nebulosa aplicación de estas y otras (como las de Mariátegui) lecturas marxistas a lo que podríamos llamar el "problema nacional”. Revueltas da a las prensas, en efecto, en 1939, un folleto titulado "La Revolución Mexicana y el proletariado" (Revueltas 1985). ${ }^{4}$ Dejándose llevar por el entusiasmo que le causaban las transformaciones realizadas por el régimen de Cárdenas, el joven Revueltas está convencido de que el país se encuentra en la antesala misma del socialismo, y que sólo falta dar un pequeño empujón para acceder a él. Curiosamente, Octavio Paz declara de modo retrospectivo algo muy semejante: "Si yo hubiese escrito El laberinto de la soledad en 1937, sin duda habría afirmado que el sentido de la explosión revolucionaria mexicana - lo que he llamado la buisqueda — terminaría en la adopción del comunismo" (Paz 1993: 38).

Una revisión de las primicias editoriales de Octavio Paz indica que él también conoció este libro fundamental, como es posible comprobarlo si se hace una lectura cuidadosa de un texto muy poco conocido que su autor dejó olvidado en las revistas Taller y Tierra Nueva y que habría escrito y publicado por esos mismos años. Me refiero a "Vigilias: diario de un soñador". En una prosa muy cercana a la de los románticos alemanes, en la que abundan las citas de Nietzsche, y en la que no faltan referencias a Engels, Scheler, Kierkegaard y Baudelaire, Paz no sólo se declara partidario de una "sociedad sin clases" y no sólo se duele de que el dinero sea "la única criatura viva del mundo burgués", sino que hace suyos los pensamientos del joven Marx y declara que el mundo capitalista es una suerte de autómata siniestro que no persigue nada sino su propio fin maquinal. Sostiene ahí Octavio Paz: "El trabajo, en el mundo capitalista, es infinito, es decir, no tiene fin, ni finalidad; no sólo no posee ningún sentido personal sino que su esencia consiste en no tener sentido y en ser impersonal, puesto que no es más que una rueda que exprime el tiempo y lo vacía, chupando toda su sustancia" (2014a: 147). ${ }^{5} \mathrm{El}$ anti-humanismo radical del capital ha logrado que el hom-

${ }^{4}$ Como lo ha hecho notar Philippe Cheron, ésta es en estricto sentido la publicación más antigua del autor, que se anticipa en un par de años a la aparición de su primera novela, Los muros de agua (1941).

5 De las cuatro "Vigilias", las dos primeras se publicaron originalmente en la revista Taller (núm. 1, de diciembre de 1938 y núm. 7, de diciembre de 1939); las dos restantes aparecieron en Tierra Nueva (enero-abril de 1941 y marzo de 1945). 
bre se convierta en "un instrumento de su instrumento", con lo cual, podríamos agregar, queda sumido en la enajenación. El dinero, quintaesencia de este sistema, se convierte en un poder autónomo y a la vez arbitrario. El diagnóstico del joven Paz es agudo y a la vez implacable:

no es una clase la que se sirve de él para expresarse y mantener su poder, es él quien se sirve de sus poseedores para realizar su fatalidad [...]. Pero el dinero no tiene fin ni objeto, es, simplemente, un mecanismo infinito, que no conoce más ley que la del círculo. Es la más pura de las realidades modernas, porque es la más abstracta. No tiene ningún sabor terrenal. No sirve para nada, puesto que no se dirige a nada. Y todos giramos en su órbita, sin salida alguna, en un mundo sin principio ni fin, vacío (148).

No está por demás recordar que todo el Manuscrito de Marx es una invectiva contra el capitalismo y que la sección III del mismo está dedicada en exclusiva al asunto del poder del dinero. De tal suerte, sostiene Marx: "La alienación se manifiesta, por una parte, porque mi medio de subsistencia pertenece a otro; porque el objeto de $m i$ deseo es el bien inaccesible de otro; y por otra parte, porque toda cosa es en sí misma otra que ella misma, porque en fin - y esto vale igualmente para el capitalista— en general domina el poder inhumano" (78). La idea del capital como un autómata carente de humanidad que ejerce un poder irresistible que avasalla con todo, está formulada aquí. Acerca del otro gran tema, el del dinero, Marx afirma, entre otras cosas: "El dinero, por el hecho que posee la propiedad de comprarlo todo, que posee la propiedad de apropiarse de todos los objetos, es, por consiguiente, el objeto en el sentido más eminente" (124). A lo que añade, después de interesantes citas de Shakespeare y de Goethe: "Puesto que el dinero, noción existente y manifiesta del valor, confunde y cambia todas las cosas, es la confusión general y el cambio de todas las cosas, por consiguiente el mundo dado vuelta [el mundo invertido], la confusión y el cambio de todas las propiedades naturales y humanas" (129-30). En otra parte del mismo texto, Marx hace referencia al carácter autotélico del dinero, noción que sin duda sirvió de base a los desarrollos de Paz: "Hasta qué punto el dinero que parece el medio es el verdadero poder y el objetivo único - hasta qué punto aquel medio que hace de mí un ser, que me apropia el ser material extraño, es su propio objetivo..." 
(77). En estos pasajes Marx insiste, para decirlo de otro modo, en que el dinero no sólo convierte en un medio a quien debiera ser un fin en si mismo: el hombre; sino que este aparente medio es en un sentido muy determinado y según los resultados prácticos un fin en sí. Esto es: un fin que se cumple a si mismo.

Aunque el complejo texto de "Vigilias", premonitorio de otros textos que Paz escribirá en su madurez, merecería una amplia revisión aparte, considero que es necesario indicar al menos dos cosas. Primero, que su conocimiento resulta indispensable si se trata de encontrar los primeros gérmenes de lo que años después se convertiría en uno de los ensayos más famosos de Paz: El arco y la lira (1956). Algunos señalamientos respecto al papel del ritmo en la creación poética, así como la idea de que en una sociedad comunista no será necesario en absoluto escribir poemas o inventar canciones pues la vida misma será poema y canción encarnados, ya se anticipan en estas prosas tan influidas por el Romanticismo. Segundo, que estas "Vigilias" también resultan de valor estratégico si se quiere acceder al análisis del poema Entre la piedra y la flor, que mencioné antes, pues este hipotexto fundador podría explicar, entre otras cosas, no sólo la rabia anticapitalista que recorre al poema, sino la sorprendente existencia de la IV sección, dedicada toda ella a la temática del dinero. Van como ejemplo unos breves pasajes pertinentes: "¡Oh rueda del dinero, / que ni te palpa ni te roza / y te deshace cada día! // [...] ¡El mágico dinero! / Sobre tus huesos se levanta, / sobre los huesos de los hombres se levanta. // Pasas como una flor por este infierno estéril, / sin llamas ni pecados, / hecho sólo del tiempo encadenado, / carrera maquinal, rueda vacía / que nos exprime y deshabita, / y nos seca la sangre, / y el lugar de las lágrimas nos mata. // Porque el dinero es infinito y crea desiertos infinitos" (2014a: 106-07). ${ }^{6}$

En cuanto a las lecturas que nos ofrecen tanto Paz como Revueltas de las propuestas contenidas en Economía politica y filosofía de Marx, que ambos habrían conocido gracias a la edición que propiciaron los exiliados alemanes a finales de los años treinta, quisiera destacar dos diferencias que se antojan fundamentales. Primero, que en Revueltas esta lectura tiene, por decirlo así, efectos retardados, de modo que se torna

${ }^{6}$ El ahora famoso Canto XLV "Con usura" de Ezra Pound se publicó por primera vez en libro en inglés en 1937, pero no hay señales de que Paz lo haya conocido en la época de la escritura de su poema. 
detectable sobre todo a partir de la publicación de Los días terrenales (1949), para dar su fruto final en la Dialéctica de la conciencia (1982); mientras que en Paz — por lo que se ha visto - los efectos son de hecho inmediatos. Segundo: que mientras a Revueltas esta lectura le permite tomar distancia de la dogmática estalinista, al ayudarle a considerar que el comunismo no es la solución del problema del ser humano, sino apenas una condición para el ejercicio cabal de su libertad; Paz accede a una original interpretación "romántica" del texto, con lo que de manera perspicaz logra evadir tanto la mediación de la teleología hegeliana como la astucia historicista de la negación de la negación. Mientras que la lectura de Revueltas reivindica sobre todas las cosas la presencia de Hegel en Marx, así como la noción de ser genérico del hombre que viene de Feuerbach (lo que da lugar a una lectura "humanista" del marxismo), Paz comprende al joven Marx como hubieran podido hacerlo los Frubromantik alemanes. Si Novalis hubiera conocido a Marx — por supuesto que se trata de una preposteración y de un imposible histórico- lo leería con los ojos con que lo leyó el joven Octavio Paz. El capitalismo es un círculo infernal; el capital, un autómata siniestro que sólo persigue sus propios fines. A través del más abstracto de sus instrumentos, el dinero, el capital vuelve al hombre instrumento de su instrumento y lo convierte literalmente en un objeto puesto a su disposición. ${ }^{7}$ En todo caso, me atrevo a sugerir, los efectos anti-estalinistas de esta precoz lectura de Marx tendrían que ver con el artículo que publicó Paz denunciado la existencia de los "campos de concentración" soviéticos en la revista Sur en 1951, tal y como lo documenta Klaus Meyer-Minnemann en Literatura Mexicana (2002).

Por lo que llevo dicho, es obvio que a Paz y a Revueltas los hermana también una temprana afición por la filosofía — que es de igual manera una vocación filosófica paralela a la literaria y casi tan importante como ella. Eso me obliga a una puntualización que tiene que ver con

7 Paz puede leer a Marx con los ojos de los Fruhromantik no sólo por su conocimiento de Novalis sino porque como en ninguno otro de sus textos, el Marx de estos Manuscritos está igualmente impregnado de nociones románticas que no pueden pasar inadvertidas. En gran medida, esta lectura es congenial al texto de Marx. Se da así algo que puede parecer a primera vista contradictorio pero que tiene que ver con la tensión interna que recorre los Manuscritos: en ellos, el joven Marx se coloca a la vez a la sombra de la dialéctica de Hegel y de los románticos alemanes, sin que éstos se excluyan mutuamente. 
la época. No sólo son ambos escritores testigos por su procedencia generacional de los primeros cambios tectónicos que está produciendo el accidentado proceso de la Revolución mexicana, igualmente son los primeros en experimentar en carne propia un singular deslizamiento en el techo sublime de las ideas. El paradigma de la filosofía francesa, que había dominado durante el porfiriato y que prevalecía todavía entre los integrantes de la generación del Ateneo de la Juventud y hasta en una parte del grupo conocido como los Contemporáneos, es sustituido por el paradigma de la filosofía alemana, con la presencia de Marx, por una parte, y por el otro con la de la nueva filosofía de corte fenomenológico, a las que sin duda se percibe como más acordes con los tiempos de transformación que vive el país. ${ }^{8}$ A Paz y Revueltas les toca en suerte pertenecer a la primera generación que crece y echa raíces dentro del esquema emergente de estas corrientes filosóficas. Sin mayores rodeos lo pone de manifiesto el propio Octavio Paz en Itinerario, cuando afirma: "La influencia de la filosofía alemana era tal en nuestra universidad que en el curso de Lógica nuestro texto de base era el de Alexander Pfänder, un discípulo de Husserl" (1993: 49).

Obsérvese bien: Paz no sostiene que haya leído por ese tiempo a Husserl, sino que el tratado de lógica que estudió en la preparatoria había sido redactado por uno de sus discípulos. ${ }^{9}$ Podría sospecharse que las primeras noticias de la fenomenología (Husserl, Scheler y Heidegger) que ya circulaban en México a finales de la década de los años veinte y principios de los treinta, gracias primero al magisterio de Adalberto García de Mendoza y, después, de Samuel Ramos, habrán de propiciar en los años cincuenta el significativo interés de Octavio Paz en el pensamiento de Heidegger, esta vez bajo el influjo personal del traductor de El ser y el tiempo al español, el profesor José Gaos. La presencia de

8 Acaso la primera señal de este "cambio" de paradigma lo constituye el enfrentamiento público entre Antonio Caso y Samuel Ramos en 1927. Juan Hernández Luna explica así esta colisión entre lo viejo y lo nuevo en asuntos de filosofía: "El ensayo de Ramos en contra de Caso [publicado en la revista Ulises, núms. 1 y 2, junio de 1927], debe interpretarse como una discrepancia entre la generación de Ramos, formado en una cultura filosófica de signo predominantemente germánico, y la generación de Caso, formado en una cultura filosófica de signo predominantemente francés" (141).

9 Guillermo Sheridan asegura, sin aportar datos, que Paz habría hecho unas "primerizas lecturas de Husserl, hacia las que lo conduce el libro de texto de Alexander Pfänder" (96). 
Heidegger se torna decisiva, como he mostrado en mi libro Las sendas perdidas de Octavio Paz (Escalante 2013), en la redacción de El arco y la lira, pero se trasmina igualmente en muchos otros textos del autor, incluso de la última época. Sin ir más lejos, la conocida sentencia de Heidegger en el sentido de que "el lenguaje es la casa del ser", la retoma con plena conciencia el Paz tardío cuando llega a afirmar que "la poesía es la casa de la presencia” (2014b). No está por demás indicar que la identificación entre "presencia" y "ser" tiene una larga tradición dentro de la historia del logocentrismo. ${ }^{10}$

Si todavía hacia el principio de los ańos cuarenta Paz y Revueltas podían compartir algunas actitudes, al menos en el campo ideológico y político, la salida de Paz primero a los Estados Unidos y luego a la Francia de la posguerra, así como su notable deriva por una parte surrealizante y por la otra heideggeriana que se produce a partir de los años cincuenta, terminarán por volverlos escritores muy diferentes. La dialéctica, el movimiento incesante de la materia, los acepta Paz tanto en el mundo material como en el de los hombres como se ve en su famoso poema Piedra de Sol (1957). El río indetenible del fluir está tanto en el caminar de río que se curva, emblemático del mundo natural, según vemos en el íncipit, como en el mundo social del personaje lírico: "voy entre galerías de sonidos, / fluyo entre las presencias resonantes". El fluir heracliteano está igual en la búsqueda ansiosa que recorre el poema: "a la salida de mi frente busco, / busco sin encontrar, busco un instante, / un rostro de relámpago y tormenta / corriendo entre los árboles nocturnos...". Pero este correr es provisional. Corresponde al tiempo del "mientras tanto" y del "todavía no". El poeta en realidad lo que persigue es una sutil epifanía que habrá de poner fin a la búsqueda y consolidará en cambio la presencia del ser, esto es, la del ser entendido como presencia plena. Por eso leemos, en los pasajes finales del texto una invocación como la que sigue: "puerta del ser: abre tu ser, despierta, / aprende a ser también... [...] / indecible presencia de presencias"

${ }^{10}$ La frase de Heidegger se encuentra en la "Carta sobre el humanismo" (Heidegger 2000: 259); la de Paz da título al primer volumen de sus Obras completas, en las que se anota, de modo pertinente, "edición del autor". La noción del lenguaje como una casa que abriga y que protege admite sutiles variaciones en el texto de Heidegger: así, la esencia del lenguaje consiste en "ser la casa de la verdad del ser." El lenguaje es "a un tiempo la casa del ser y la morada de la esencia del hombre". Por último: "el lenguaje es el lenguaje del ser, como las nubes son las nubes del cielo” (263, 295 y 297). 
(1990: 260, 262, 277). Con un gesto poderoso e impregnado de dialéctica, que ya no inicia sino consuma el periplo reflexivo, la epifanía pone al poeta otra vez de frente al fluir natural. Pero este fluir ha sido neutralizado y es parte de una riqueza del ser acumulable por la figura del poeta, cuya tentativa ha llegado a puerto. Lo dirá en otros términos al concluir su discurso de recepción del Premio Nobel en 1990. Da a entender ahí Paz que al final lo que resplandece es la presencia, sin duda otro nombre del ser que alcanza a detectarse por los sentidos y que por ello sería peculiarmente efectivo. Por eso atreve una suerte de profecía filosófica a cumplirse en un futuro próximo: "Así como hemos tenido filosofías del pasado y del futuro, de la eternidad y de la nada, mañana tendremos una filosofía del presente. La experiencia poética puede ser una de sus bases." ¿Qué sabemos del presente?, se pregunta el autor. De inmediato responde: "Nada o casi nada. Pero los poetas saben algo: el presente es el manantial de las presencias" (2014c: 549). El corolario de Paz, por lo demás inevitable, está en lo que sigue. Con ello, en realidad, concluye su discurso: "Entonces las puertas de la percepción se entreabren y aparece el otro tiempo, el verdadero, el que buscábamos sin saberlo: el presente, la presencia” (550).

José Revueltas, en cambio, fiel a su concepto de despersonalización se entrega a ese fluir de la realidad que él llama su "lado moridor". No le interesa que se abran las puertas del ser ni las de la percepción, o que se instaure soberano el reino de la presencia; lo que intenta es dejarse llevar por el flujo mismo de la realidad (un flujo sin duda heracliteano, pero entendido en toda su eficacia a partir de sus lecturas de Hegel) que supera la realidad de su conciencia. La tarea del escritor no es imponer su voluntad a los materiales literarios que él habría escogido, sino dejarse llevar por ellos tratando de encontrar la tendencia a que obedecen estos mismos materiales, y de seguirla en todo. La subjetividad del autor, de tal suerte, podrá fundirse con la realidad objetiva e identificarse con ella, pero sólo a un costo que implica la "desaparición" misma del autor. Cuando esto sucede, asegura Revueltas: "Obtenida esta identidad teórica, el pensamiento subjetivo se transforma en pensamiento objetivo: ya que es la cosa real que se piensa a sí misma, como tal cosa, en el cerebro del hombre". A consecuencias de ello, según Revueltas, "la realidad objetiva se autoanaliza en el pensamiento humano y se convierte en praxis" (1978: 224). Como quien dice, el flujo universal se autoobjetiva al apoderarse del cerebro del escritor, convirtiéndose con ello 
en reflexión, es decir, en autoconciencia, con lo que puede ya recalar en el tormentoso terreno de la acción. Mayor prueba de hegelianismo no podríamos encontrar.

\section{BibLIOGRAFÍA}

Escalante, Evodio. Las sendas perdidas de Octavio Paz. México: Ediciones Sin Nombre / Universidad Autónoma Metropolitana-Iztapalapa, 2013.

Fuentes Morúa, Jorge. José Revueltas. Una biografía intelectual. México: Miguel Ángel Porrúa / Universidad Autónoma Metropolitana-Iztapalapa, 2001.

Fuentes Morúa, Jorge. "El exilio alemán en México y la difusión del marxismo", en Pacarina del Sur. Revista de pensamiento crítico latinoamericano. Disponible en línea en <www.pacarinadelsur.com/huellas-y-voces/79el-exilio-aleman-en-mexico-y-la-difusion-del-marxismo $>$ [consultado el 02/12/2014].

Heidegger, Martin. Hitos. Trad. de Helena Cortés y Arturo Leyte. Madrid: Alianza Editorial, 2000.

Hernández Luna, Juan. "La polémica sobre el magisterio de Antonio Caso", en Antonio Caso. Obras completas, I. Polémicas. México: Universidad Nacional Autónoma de México, 1971.

Marx, Carlos. Economía politica y filosofía. Relaciones de la economía politica con el Estado, el derecho, la moral y la vida burguesa. Trad. de A[licia]. G[erstel]. Rühle y J [osé]. Harari. México: Editorial América [1939].

Meyer-Minnemann, Klaus. "Octavio Paz, David Rousset y el universo de los campos de concentración”, en Literatura Mexicana, XIII.1 (2002): 149-172.

Paz, Octavio. Obra poética (1935-1988). México: Seix Barral, 1990.

Paz, Octavio. Itinerario. México: Fondo de Cultura Económica, 1993.

Paz, Octavio. Obras completas VIII. Miscelánea. Primeros escritos y entrevistas. México: Fondo de Cultura Económica, $2014 a$.

Paz, Octavio. Obras completas I. La casa de la presencia. Poesía e historia. México: Fondo de Cultura Económica, 2014 b.

Paz, Octavio. Obras completas II. Excursiones e incursiones / Fundación y disidencia. México: Fondo de Cultura Económica, 2014c.

Revueltas, José. Cuestionamientos e intenciones. México: Ediciones Era, 1978.

Revueltas, José. Ensayos sobre México. México: Ediciones Era, 1985. 
Revueltas, José. El propósito ciego [Poemas]. Edición de José Manuel Mateo. México: Editorial Aldus-Obra Negra, 2001.

Sheridan, Guillermo. Poeta con paisaje. Ensayos sobre la vida de Octavio Paz. México: Ediciones Era, 2004. 